\title{
Comparison of UV-C irradiation, ozonation, and iron chelates treatments for degradation of tetracycline in water
}

\author{
A. Ziółkowska ${ }^{1} \cdot$ M. Margas ${ }^{1} \cdot$ H. Grajek ${ }^{2} \cdot$ J. Wasilewski $^{3} \cdot$ B. Adomas ${ }^{4} \cdot$ \\ D. Michalczyk ${ }^{1}$ - A. I. Piotrowicz-Cieślak ${ }^{1}$
}

Received: 2 December 2015/Revised: 22 February 2016/Accepted: 28 February 2016/Published online: 4 April 2016

(C) The Author(s) 2016. This article is published with open access at Springerlink.com

\begin{abstract}
The objective of this study was to propose a method for efficient degradation of tetracycline as a water contaminant. UV-C rays, ozonation, and iron chelates were used for removal of tetracycline from water. Aqueous solution of tetracycline $\left(5 \times 10^{-5} \mathrm{M}\right)$ was exposed to UV$\mathrm{C}$ rays (in two doses-6 and $12 \mathrm{~W}$ ), ozonation (at 6-12 mg ozone), or iron chelates: iron(III) sodium ethylenediaminetetraacetate, iron(III) trisglycinate, and iron(III) citrate. For each of iron compounds, three doses were studied: $2.5 \times 10^{-5} \mathrm{M}, 5 \times 10^{-5} \mathrm{M}, 10 \times 10^{-5} \mathrm{M}$. The experiments have shown that aqueous solution of tetracycline $\left(5 \times 10^{-5} \mathrm{M}\right)$ is immediately degraded as a result of ozonation with $12 \mathrm{mg}$ ozone. Absorbance of tetracycline decreased from $A=0.78$ to $A=0.35$ after 20-min ozone treatment of sample. The fluorescence spectra revealed the presence of two ozone-induced TC degradation products with fluorescence maxima at 523 and $531 \mathrm{~nm}$ appearing immediately after the ozonation treatment. On the other
\end{abstract}

A. I. Piotrowicz-Cieślak

acieslak@uwm.edu.pl

1 Department of Plant Physiology, Genetics and Biotechnology, Faculty of Biology and Biotechnology, University of Warmia and Mazury in Olsztyn, Oczapowskiego 1A, 10-718 Olsztyn, Poland

2 Department of Physics and Biophysics, Faculty of Food Science, University of Warmia and Mazury in Olsztyn, Oczapowskiego 4, 10-719 Olsztyn, Poland

3 Department of Biochemistry, Faculty of Biology and Biotechnology, University of Warmia and Mazury in Olsztyn, Oczapowskiego 1A, 10-718 Olsztyn, Poland

4 Department of Environmental Toxicology, Faculty of Environmental Management and Agriculture, University of Warmia and Mazury in Olsztyn, Prawocheńskiego 17, 10-720 Olsztyn, Poland hand, iron(III) sodium ethylenediaminetetraacetate and iron(III) trisglycinate gave rise to a single TC degradation product with a fluorescence maximum at $531 \mathrm{~nm}$, observed after 10 days of the experiment. On application of iron(III) trisglycinate, at any studied concentration, tetracycline becomes degraded faster-in 4 days. Iron(III) citrate degraded $90 \%$ of tetracycline, when used at the level $10 \times 10^{-5} \mathrm{M}$. The biggest changes in tetracycline concentration were obtained as a result of ozonation and iro$\mathrm{n}$ (III) citrate treatments.

Keywords Antibiotic - Contamination - Iron(III) citrate · Iron(III) sodium ethylenediaminetetraacetate · Iron(III) trisglycinate

\section{Introduction}

Chemicalization of industry and excessive consumption result in mankind-producing ever-growing amounts of chemicals and environmental contaminants. Environmental pharmaceuticals are a rather new kind of pollutants.

Tetracyclines are present in all the elements of the environment, even in treated sewage, and the efficiency of their removal in sewage-treatment plants is very low (Miao et al. 2004). Tetracyclines are among the most commonly used antibiotics worldwide (Gu et al. 2007; O'Connor and Aga 2007; Hao et al. 2012). Since they are poorly absorbed and are excreted in substantial amounts in the digestive tract of animals (about 50-80 \%) with feces and urine (Wu et al. 2011; Kong et al. 2012), tetracycline is detected in manure and slurry. The concentrations of tetracycline in pig manure are $23 \mathrm{mg} / \mathrm{kg}$ (Martínez-Carballo et al. 2007). In fresh chicken manure, the highest detected limit of tetracycline was $16.75 \mathrm{mg} / \mathrm{kg}$ (Zhang et al. 2008). 
Fertilization of fields with animal waste significantly contributes to the spread of antibiotics in the environment (Kwon et al. 2011), pharmaceutical factories, hospital and municipal waste waters (Bagda et al. 2013). Environmental tetracycline retains its antibacterial properties (Chander et al. 2005). It was found that only $50 \%$ of the tetracycline in manure is degraded after 5 months, and it may be detected in soil for periods of several months to years (Hamscher et al. 2005; Rosendahl et al. 2012). Moreover, tetracyclines are characterized by a strong and durable adsorption to soil particles and are resistant to biodegradation (Safari et al. 2015). Tetracycline can be taken up from water and soil and accumulated in plants, thus entering the trophic chains (Zhao et al. 2010; Wei et al. 2009; Ziółkowska et al. 2015).

This new kind of pollutants can be removed from the environment by using various sorbents or carrying out the degradation of the pharmaceutics in the whole volume of waste water. Among the techniques of removal tetracycline-like antibiotics, adsorption is regarded one of the most efficient. It is carried out mainly on modified activated carbons; however, due to a broad range of chemical structures, it is not easy to find one universally applicable adsorbent. It should be emphasized that the efficiency of sorption depends on surface activation, active sites and porosity, flow rate, initial concentration, external mass transfer coefficient and $\mathrm{pH}$ (Saleh and Gupta 2014). A high $\mathrm{pH}$ value is preferred for cationic pollutant adsorption while a low $\mathrm{pH}$ value is preferred for anionic pollutant adsorption. Other frequently used adsorbents include carbon nanotubes (Gupta et al. 2013), pillared clays (e.g., bentonites; Lezehari et al. 2012). Zeolite beta was also applied for removal of tetracyclines. The amino functional groups of tetracycline were bound with complex bonds to the surface of zeolite. Aluminum atoms of zeolite played a significant role in this uptake. The adsorption of tetracyclines increases with increasing aluminum content (Kang et al. 2011). Activated carbon from Iris tectorum ferric nitrate ( $\mathrm{Li}$ et al. 2013) and graphene (Zhao et al. 2015) has also been successfully applied. Photocatalytic degradation catalyzed by semiconductors seems to be a particularly promising attitude (Gupta et al. 2012). However, the most frequently recommended way of pharmaceutics degradation in waste water (even at an industrial/technological scale) is ozonation. It is commonly applied for preparation of drinking water for supply systems. However, for degradation of diclofenac (a non-steroid anti-inflammatory drug), UV treatment is more efficient (Naddeo et al. 2012). Similarly, only a low degree of amoxicillin mineralization was found even after long period of ozonation treatment (Andreozzi et al. 2005). Sulfamethazine, on the other hand, undergoes a quick degradation under ozonation treatment (Adams et al., 2002). Ternes et al. (2003) reported that ozone applied at the level of $5 \mathrm{mg} / \mathrm{l}$ totally eliminates (i.e., converts) sulfamethoxazoles in waste waters.

The objective of this study was to determine the rate of tetracycline degradation in water treated with UV-C rays or subjected to ozonation or aqueous solutions of iron chelates: iron(III) sodium ethylenediaminetetraacetate, iro$\mathrm{n}(\mathrm{III})$ trisglycinate, and iron(III) citrate.

\section{Materials and methods}

Tetracycline (Fig. 1), CAS number 60-54-8, $\geq 98.0 \%$ (NT) was purchased from Sigma-Aldrich company. All solutions were prepared using ultrapure water (Millipore Milli- $Q^{\mathrm{R}}$ ). Aqueous solution of tetracycline $\left(5 \times 10^{-5} \mathrm{M}\right)$ was subjected to UV-C rays provided by a fluorescent tube TUU $15 \mathrm{~W} / \mathrm{G} 15 \mathrm{~T} 8$ (Philips) at two doses $(6$ and $12 \mathrm{~W})$. The irradiation was carried out from the distance of $50 \mathrm{~cm}$ for 10 and $20 \mathrm{~min}$. Another tetracycline solution, of the same concentration, was ozonated using SPALAB ozone generator (ECO-OZON P.H.U., Poland). The ozone generation intensity was tuned to the $50 \%$ level $(50 \mathrm{mg}$ ozone/h) and carried out for 10-20 min, which corresponded to 6 and $12 \mathrm{mg}$ ozone content in analyzed samples.

Iron(III) sodium ethylenediaminetetraacetate $\mathrm{Na}\left[\mathrm{Fe}\right.$ (EDTA)] $3 \mathrm{H}_{2} \mathrm{O}$ (Fig. 2) was prepared by common method (Resource Book for Sixth-form Practical Chemistry 2015). Iron(III) trisglycinate [Fe(III)GLY] (Fig. 3) was synthesized according to the literature (Abd-Elmoneim et al. 2008). The commercially available iron(III) citrate [Fe(III)CIT] (Fig. 4) (International Enzymes Limited, pure) was additionally purified following a patented method (Ando and Manta 2015). The obtained compounds were used to prepare solutions containing $5 \times 10^{-5} \mathrm{M} \mathrm{TC}$ and iron chelates $(\mathrm{Na}[\mathrm{Fe}(\mathrm{EDTA})], \mathrm{Fe}(\mathrm{III}) \mathrm{GLY}$, or $\mathrm{Fe}(\mathrm{III})$ CIT) at $2.5 \times 10^{-5} \mathrm{M}, 5 \times 10^{-5} \mathrm{M}$, or $10 \times 10^{-5} \mathrm{M}$. The initial $\mathrm{pH}$ of iron chelates was 5.0, and at the end of the experiment, it was 6.0; the $\mathrm{pH}$ measurements were made every day for 10 days.

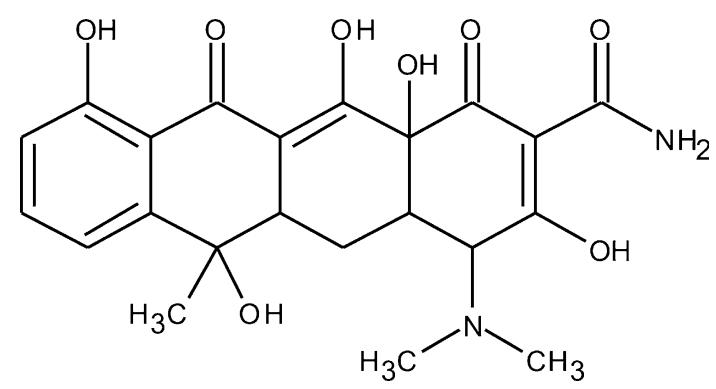

Fig. 1 Chemical structure of tetracycline (TC) 


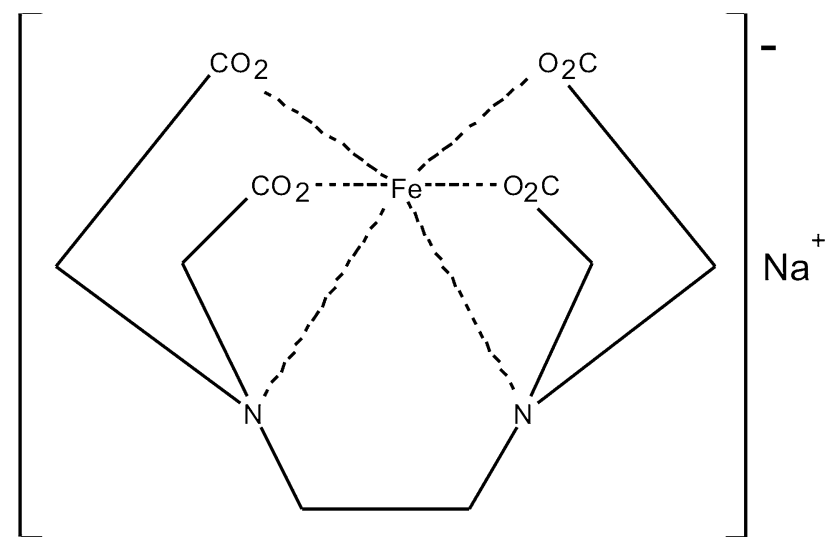

Fig. 2 Chemical structure of iron(III) sodium ethylenediaminetetraacetate $(\mathrm{Na}[\mathrm{Fe}(\mathrm{EDTA})])$

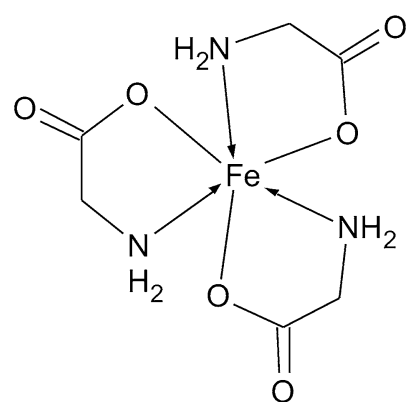

Fig. 3 Chemical structure of iron(III) trisglycinate (Fe(III)TGLY)

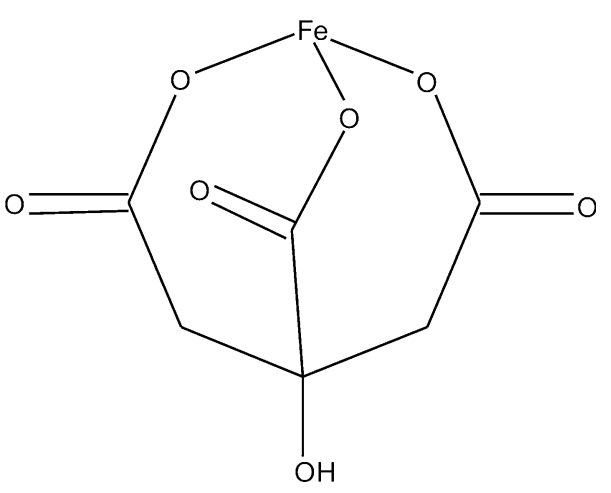

Fig. 4 Chemical structure of iron(III) citrate (Fe(III)CIT)

The absorption spectra were measured using the Carry 300 UV-Visible Spectrophotometer (Varian, Inc.). The fluorescence spectra were measured with a Cary Eclipse Fluorescence Spectrophotometer (Varian, Inc.) using rightangle geometry. The excitation slit width was $20 \mathrm{~nm}$, and emission slit width was $20 \mathrm{~nm}$ for all measurements. With all samples, excitation was at $\lambda_{\text {exc }}=360 \mathrm{~nm}$. Absorption and emission spectra were determined at room temperature.

\section{Results and discussion}

In recent years, drugs have been detected in all major subsystems of the environment (in soils, surface waters, ground water, and even drinking water, in plants and animal organisms) (Liu et al. 2014). Tetracyclines are a group of drugs widely used all over the world, both in human medicine and in veterinary medicine. The US Environmental Protection Agency (US EPA 2009) indicates that it is not possible to remove pharmaceuticals in sewagetreatment plants, as they lack equipment for drug removal. Among the household/anthropogenic pollutants, drugs raise the deepest concerns as they may contribute to the development of antibiotic-resistant bacteria (Mohanta and Goel 2014; Sidrach-Cardona et al. 2014). Research is conducted concerning the removal of TC from the environment. Ozonation is one of the most common methods of water treatment in Europe, USA, and North America (Tay and Madehi 2015).

The use of ozonation in water treatment includes comprehensive oxidation pathways, which can lead to the formation of various by-products, some of which can be harmful to living organisms. During hydroxylation, ofloxacin is divided at the unsaturated double bond of the heterocyclic ring (Tay and Madehi 2015). In addition, ozonation leads to the degradation of water solutions of oxalic acid and oxamic acid and formation of the final products of their oxidation (Orge et al. 2015).

In our project, we studied TC degradation during a 10 day period as a result of the following treatments: ozone, UV, $\mathrm{Na}$ [Fe(EDTA)], Fe(III)TGLY, and Fe(III)CIT at various concentrations. The breakdown of TC was detected by determination of fluorescence and absorption spectra of the analyzed solutions.

\section{Absorption spectra}

Figure 5a shows the absorption spectra of tetracycline in aqueous solutions measured every day for 10 days. Two absorption bands (I and II) corresponding to the transitions $\mathrm{S}_{1} \leftarrow \mathrm{S}_{0}$ (from singlet ground state $\mathrm{S}_{0}$ to excited singlet state $S_{1}$ ) and $S_{2} \leftarrow S_{0}$ (from singlet ground state $S_{0}$ to excited second singlet state $S_{2}$ ). They have maxima at a wavelengths of $\lambda_{\max }=357 \mathrm{~nm}$ and $\lambda_{\max }=275 \mathrm{~nm}$. Energy level diagram for TC with transitions from ground state $S_{0}$ to $S_{1}$ and $S_{2}$ states is shown in Fig. 5b. Calculated energy values corresponding to $S_{1} \leftarrow S_{0}$ and $S_{2} \leftarrow S_{0}$ transitions are shown in Table 1.

Figure $6 \mathrm{a}, \mathrm{b}$ show the absorption spectra of TC subjected to UV-C rays and Fig. 6c, d show the absorption spectra of TC treated with ozone for 10 and $20 \mathrm{~min}$. 
Fig. 5 a The absorption spectra of TC solution in water, b energy diagram for TC electronic band peaks. Diagram for tetracycline electronic band peaks. Singlet states, $\mathrm{S}_{1}$ - first excited state, $\mathrm{S}_{2}$ - second excited state, are corresponding to TC electronic absorption peaks shown in a. Arrows $I$ and $I I$ show the transitions from singlet ground state $S_{0}$ to excited states $S_{1}$ and $\mathrm{S}_{2}$, correspondingly

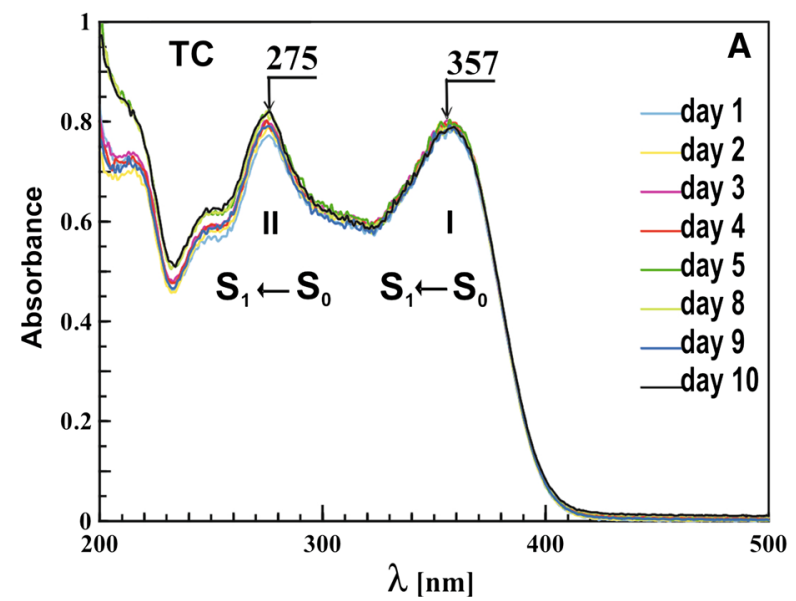

Table 1 Spectroscopic data of TC absorption bands in water solutions

\begin{tabular}{llll}
\hline Absorption band & $\lambda(\mathrm{nm})$ & $\bar{v}\left(\mathrm{~cm}^{-1}\right)$ & $E^{*}(\mathrm{eV})$ \\
\hline I & $357 \pm 1$ & $28010 \pm 80$ & $3.48 \pm 0.01$ \\
II & $275 \pm 1$ & $36360 \pm 80$ & $4.51 \pm 0.01$ \\
\hline
\end{tabular}

$E=h \frac{c}{\lambda}$ energy transition from ground to excited states, $h$ Planck's constant, $c$ light velocity, $\bar{v}$ the wave number, $\lambda$ wavelength corresponding to absorption peaks I and II

Additionally, absorption spectrum of control TC solution, not treated with ozone, is shown in these figures (the curve labeled TC). As can see from Fig. 6a, b, UV-C irradiation hardly affects the absorption spectrum. The ozonation treatment, on the other hand, clearly affects the absorption spectra of TC solutions. Absorbance of TC decreased from $A=0.78$ to $A=0.50$ after 10 -min ozone treatment of sample (Fig. 6c). A large decrease in TC absorbance from $A=0.78$ to $A=0.35$ can be seen, particularly after 20-min ozonation treatment of sample (Fig. 6d). These results indicate that the degradation products are continuously formed during the ozone treatment. Dalmázio et al. (2007) also observed a deep decrease in TC absorption as a result of ozonation. UV absorbance can be used in a sewage-treatment plant as a control parameter which allows to quickly obtain an overview of process capability and stability of ozonation (Wittmer et al. 2015). UV-C light, wavelengths $200-280 \mathrm{~nm}$, with $90 \%$ emission at $253.7 \mathrm{~nm}$, has long established applications in food surface decontamination due to its antimicrobial capacity (FDA 2002).

Figure 7 shows changes in absorption spectra of TC resulting from a 10-day-long treatment with $\mathrm{Na}[\mathrm{Fe}(\mathrm{EDTA})]$, at different TC: $\mathrm{Na}[\mathrm{Fe}(\mathrm{EDTA})]$ ratios: a) $2: 1 \quad\left(C_{\mathrm{TC}}=5 \times 10^{-5} \mathrm{M}: C_{\mathrm{Na}[\mathrm{Fe}(\mathrm{EDTA})]}=2.5 \times 10^{-5} \mathrm{M}\right.$, Fig. 7a $)$ b) $1: 1 \quad\left(C_{\mathrm{TC}}=5 \times 10^{-5} \mathrm{M}: C_{\mathrm{Na}[\mathrm{Fe}(\mathrm{EDTA})]}=\right.$
$5 \times 10^{-5} \mathrm{M}, \quad$ Fig. $\left.7 \mathrm{~b}\right), \quad$ c) $\quad 1: 2 \quad\left(C_{\mathrm{TC}}=5 \times 10^{-5}-\right.$ $\mathrm{M}: C_{\mathrm{Na}[\mathrm{Fe}(\mathrm{EDTA})]}=10 \times 10^{-5} \mathrm{M}$, Fig. $\left.7 \mathrm{c}\right)$. The spectrum of pure $\mathrm{Na}[\mathrm{Fe}(\mathrm{EDTA})]$ is also shown in each figure. The biggest changes in TC absorption spectra are visible in variants in which $\mathrm{Na}[\mathrm{Fe}(\mathrm{EDTA})]$ concentration was twice that of TC (Fig. 7c). In this variant solution, absorbance decreased from $A=0.88$ to $A=0.53$. All absorption spectral lines intersect at one isosbestic point which suggests an equilibrium between two components of the solution: TC and its degradation products. Llorca et al. (2014) have demonstrated that the addition of $0.1 \%$ EDTA to a TC solution during storage at $-20{ }^{\circ} \mathrm{C}$ for 12 weeks did not cause the degradation of tetracycline. On the other hand, Wang et al. (2016) has shown that Fe(III) ions enhanced the degradation rate of TC, oxytetracycline and chlortetracycline by up to 20.67, 7.07 and 2.30 times, respectively, in clean water and wastewater.

Similar changes in absorption spectra were observed in TC incubated for 10 days with Fe(III)TGLY (see Fig. 8). In the variant of this experiment with concentration ratio $C_{\mathrm{TC}}=5 \times 10^{-5} \mathrm{M}: C_{\mathrm{Fe}(\mathrm{III}) \mathrm{TGLY}}=10 \times 10^{-5} \mathrm{M}$, Fig. $\left.8 \mathrm{c}\right)$, the absorbance decreased from $A=0.81$ to $A=0.52$. The isosbestic point was seen throughout the 10-day period and its location did not change, and it occurred constantly at wavelength $\lambda=393 \mathrm{~nm}$. This should be interpreted again as an indication of a state of equilibrium of TC and product of its degradation.

The biggest changes in absorption spectra of TC solutions were visible after a 10-day treatment when Fe(III)CIT was used (Fig. 9). At the TC:Fe(III)CIT concentration ratio $2: 1$, the isosbestic point is very distinct (Fig. 9a). It moved slightly toward a shorter wave length range after 4 days (Fig. 9a). However, at TC:Fe(III)CIT concentration ratios $1: 1$ and 1:2, the isosbestic point becomes blurred after 4 and 3 days, respectively, and a nearly complete degradation of TC occurs and the spectra no longer resemble that of TC (Fig. 9b, c). The solutions became turbid, as 

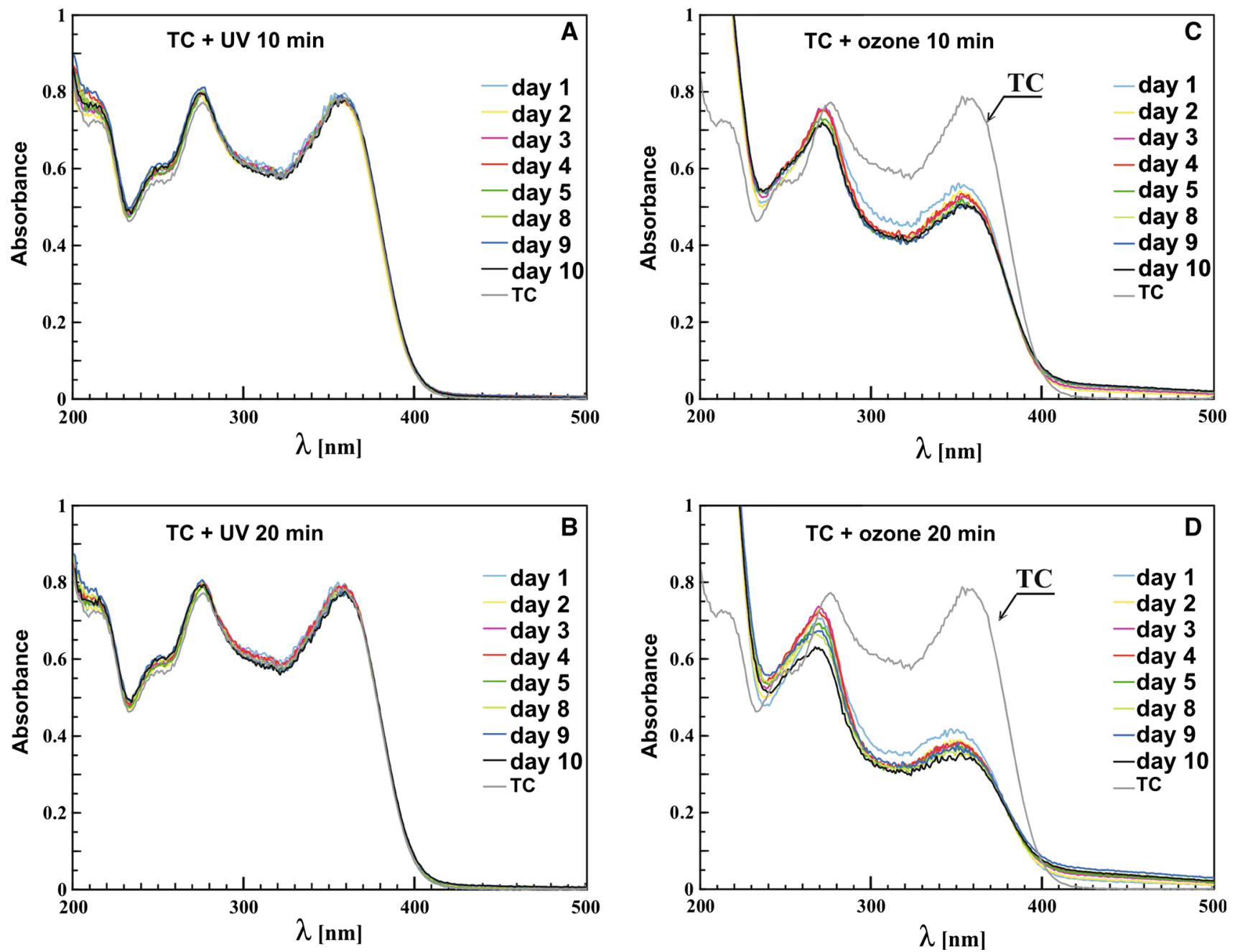

Fig. 6 The changes in the absorption spectra of TC (during 10 days) after treatments: with UV for 10 (a) and 20 min (b), with ozone for 10 min (c), and $20 \mathrm{~min}(\mathbf{d})$. Standard deviation for TC sample with UV ranged from 0.004 to 0.01 , and SD for TC treated with ozone was 0.004 to 0.006

indicated by high absorbance at wavelengths around $500 \mathrm{~nm}$. The higher Fe(III)CIT concentration accelerated complete TC degradation even further. Mixture of a tetracycline and Fe(III)CIT is an extremely sophisticated system (Chen 2008). TC is susceptible to various transform reactions including isomerization, dehydration, substitution, and oxygenation. Fe(III)CIT system is light sensitive. Despite the fact that numerous papers have been published, concerning Fe(III)CIT speciation in aqueous solution, our present knowledge of $\mathrm{Fe}(\mathrm{III})$ complexation by citrate anion still remains fuzzy (Vukosav et al. 2012). Both of the investigated compounds have multiple ionizable functional groups, and their speciation strongly depends on $\mathrm{pH}$ value of solution. It is assumed that in pure solution, tetracycline can form several different molecular species; however, at $3.4<\mathrm{pH}<7.6$ one form (described as $\mathrm{H}_{2} \mathrm{~L}$ ) clearly predominates (Kang et al. 2010). Any other components added to the TC solution can significantly distort the equilibria between different TC species. It was clearly demonstrated for complex iron(III) ions (Wang et al. 2016). In our experiments, $\mathrm{pH}$ varied within a narrow range 5.0-6.0. The wavelength of the absorption maximum did not shift during the experiment, which indicates that the $\mathrm{pH}$ value did had no effect on the way of TC degradation. This result corroborates the observation by Mojica et al. (2014) that the $\mathrm{pH}$ shift within the above given limit does not affect the TC solution absorption spectrum.

\section{Fluorescence}

The fluorescence spectrum of TC (Fig. 10a) consists of a single band with the absorption maximum at wavelength $\lambda=576 \mathrm{~nm}$. According to the Kasha's rule, fluorescence may only result from electron transition from its lowest vibrational state $S_{1}$ (Fig. 5b). Therefore, there is no surprise that only one fluorescence band is observed. 

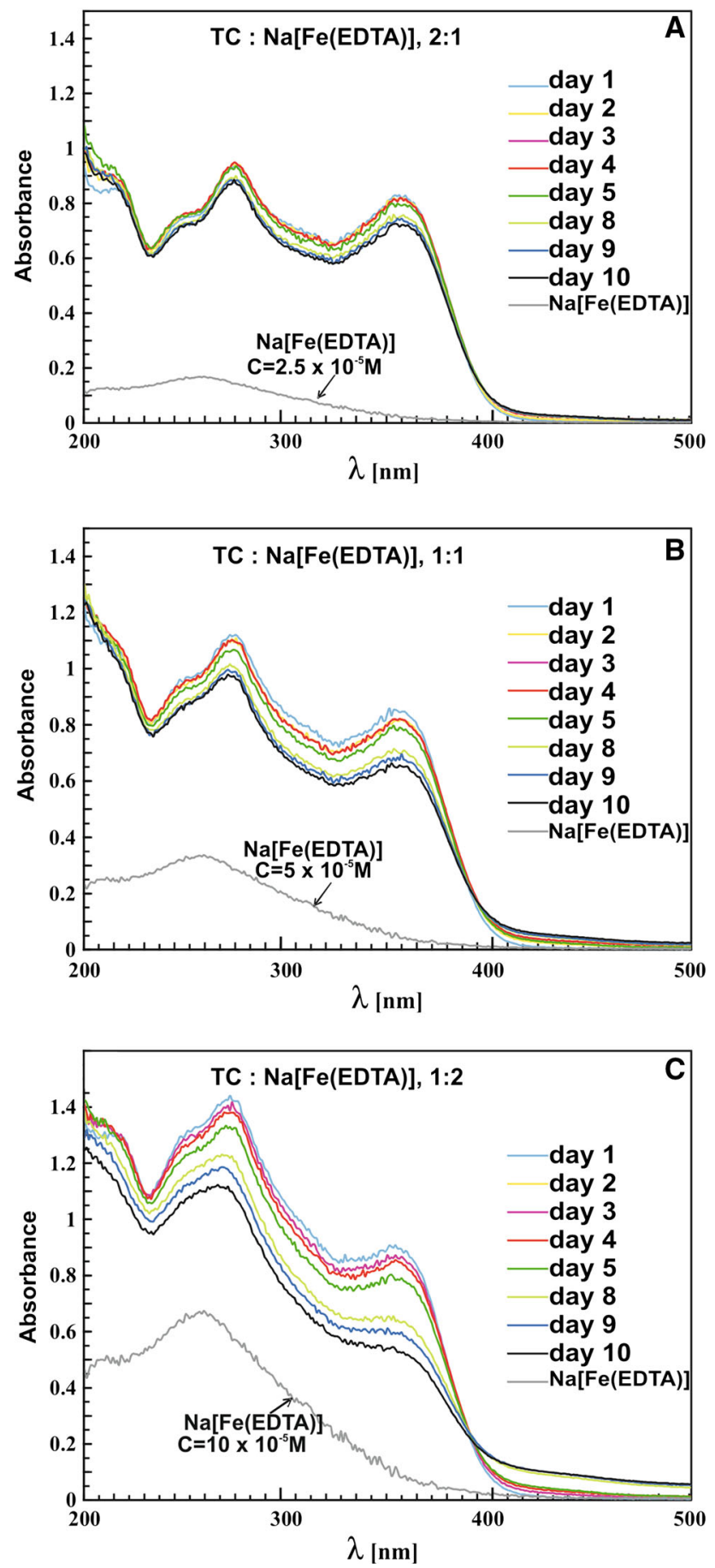

Fig. 7 The changes of absorption spectra of TC (during 10 days) for different initial molar concentration ratios of TC to NA[Fe(EDTA)]: a $2: 1 \quad\left(C_{\mathrm{TC}}=5 \times 10^{-5} \mathrm{M}: C_{\mathrm{Na}[\mathrm{Fe}(\mathrm{EDTA})]}=2.5 \times 10^{-5} \mathrm{M}\right)$, b $1: 1$ $\left(C_{\mathrm{TC}}=5 \times 10^{-5} \mathrm{M}: C_{\mathrm{Na}[\mathrm{Fe}(\mathrm{EDTA})]}=5 \times 10^{-5} \mathrm{M}\right)$, c $1: 2\left(C_{\mathrm{TC}}=\right.$ $\left.5 \times 10^{-5} \mathrm{M}: C_{\mathrm{Na}[\mathrm{Fe}(\mathrm{EDTA})]}=10 \times 10^{-5} \mathrm{M}\right)$. Each figure is supplemented with a spectrum of pure $\mathrm{NA}[\mathrm{Fe}(\mathrm{EDTA})]$. Absorbance standard deviation for TC sample treated with $\mathrm{NA}[\mathrm{Fe}(\mathrm{EDTA})]$ in ratio 2 : 1 ranged $0.002-0.03$, in ratio $1: 1$ was $0.011-0.035$, and SD in ratio $1: 2$ ranged $0.035-0.07$
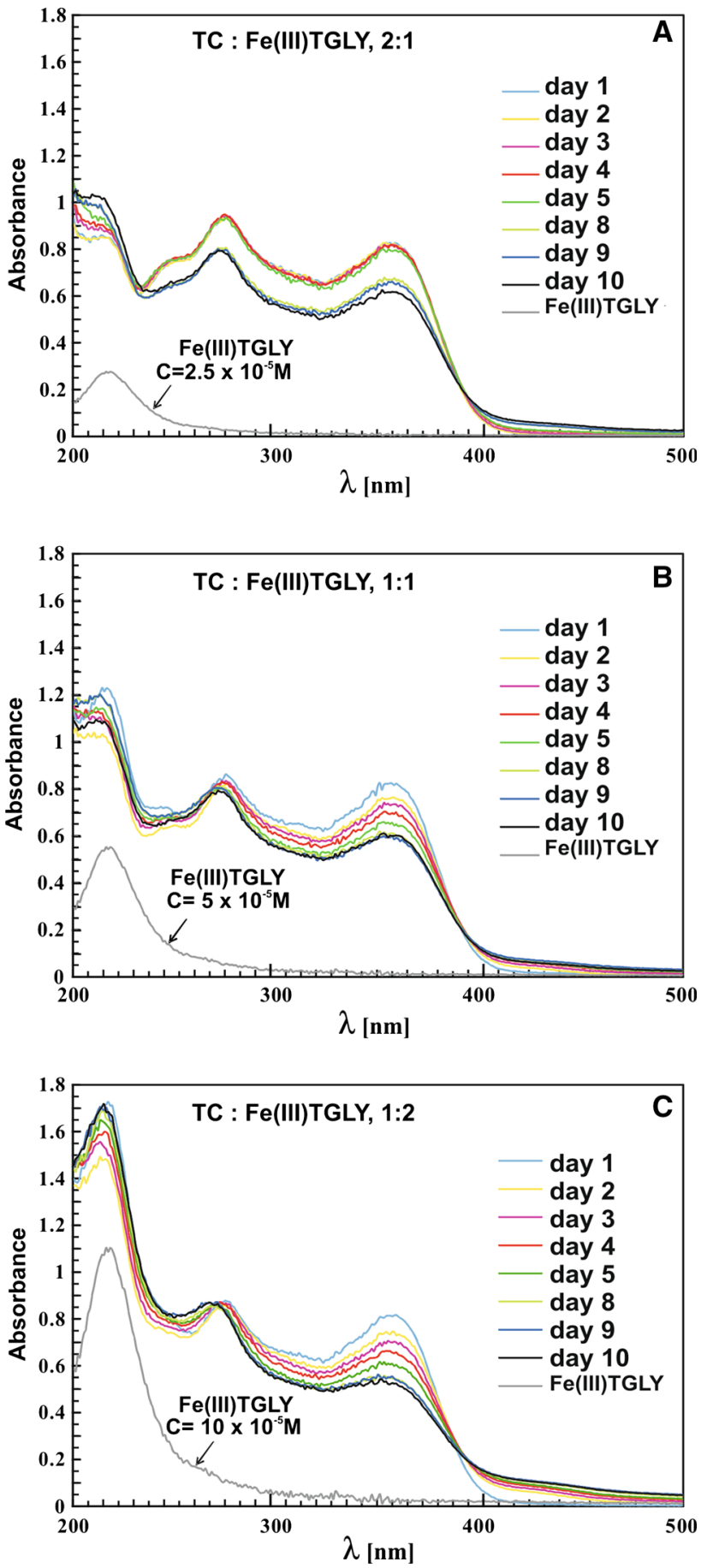

Fig. 8 The changes of absorption spectra of TC (during 10 days) for different initial molar concentration ratios of TC to Fe(III)TGLY: a $2: 1 \quad\left(C_{\mathrm{TC}}=5 \times 10^{-5} \mathrm{M}: C_{\mathrm{Fe}(\mathrm{III}) \mathrm{TGLY}}=2.5 \times 10^{-5} \mathrm{M}\right)$, b $1: 1$ $\left(C_{\mathrm{TC}}=5 \times 10^{-5} \mathrm{M}: C_{\mathrm{Fe}(\mathrm{III}) \mathrm{TGLY}}=5 \times 10^{-5} \mathrm{M}\right)$, с $1: 2 \quad\left(C_{\mathrm{TC}}=\right.$ $\left.5 \times 10^{-5} \mathrm{M}: C_{\mathrm{Fe}(\mathrm{III}) \mathrm{TGLY}}=10 \times 10^{-5} \mathrm{M}\right)$. Absorbance standard deviation for TC sample treated with Fe(III)TGLY in ratio of 2:1 ranged $0.005-0.04$, in ratio $1: 1$ was $0.01-0.035$, and SD in ratio $1: 2$ was $0.02-0.03$ 

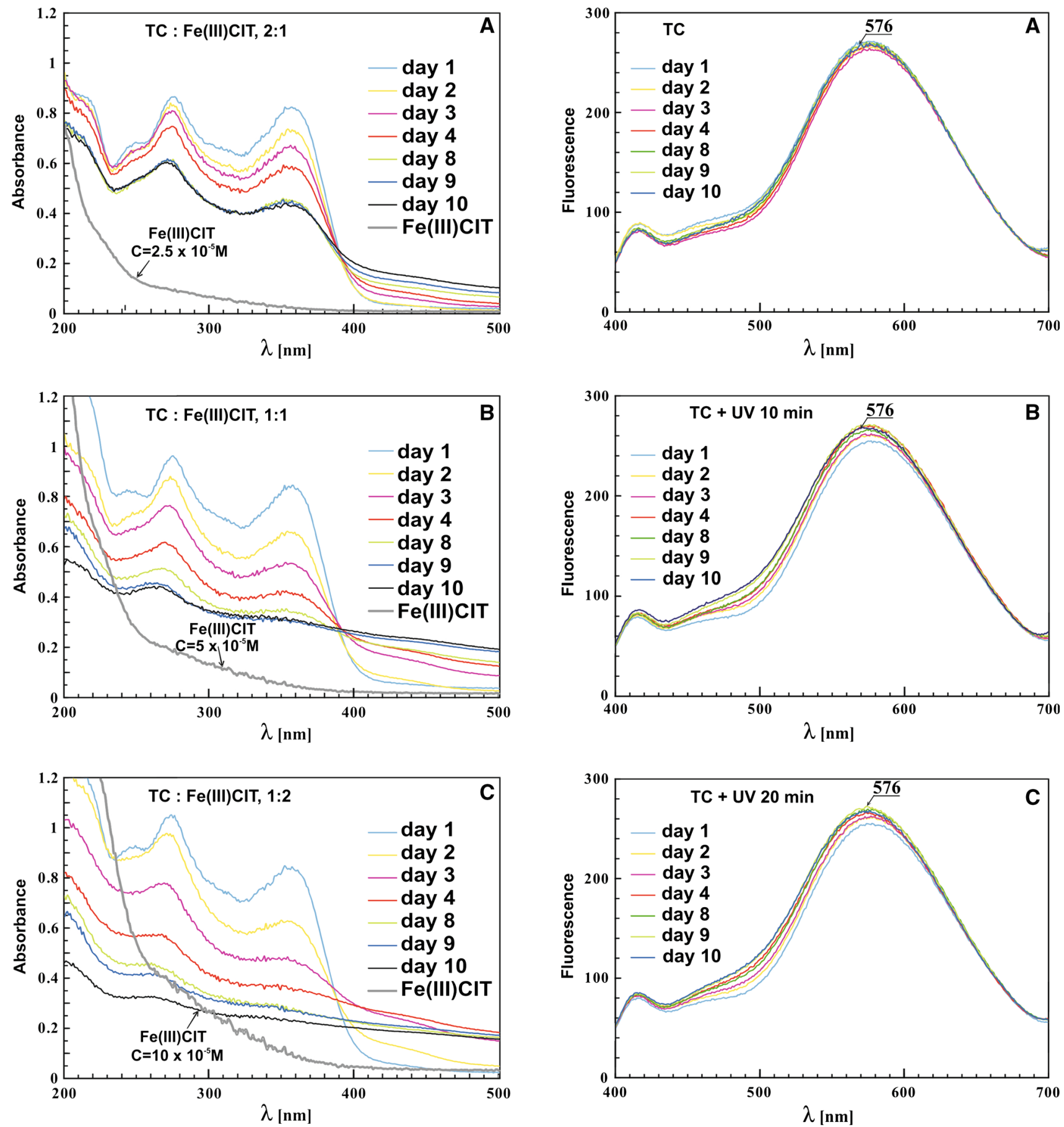

Fig. 9 The changes of absorption spectra of TC (during 10 days) for different initial molar concentration ratios of TC to Fe(III)CIT: a 2:1 $\left(C_{\mathrm{TC}}=5 \times 10^{-5} \mathrm{M}: C_{\mathrm{Fe}(\mathrm{III}) \mathrm{CIT}}=2.5 \times 10^{-5} \mathrm{M}\right), \quad$ b $1: 1 \quad\left(C_{\mathrm{TC}}=\right.$ $\left.5 \times 10^{-5} \mathrm{M}: C_{\mathrm{Fe}(\mathrm{III}) \mathrm{CIT}}=5 \times 10^{-5} \mathrm{M}\right)$, c $1: 2\left(C_{\mathrm{TC}}=5 \times 10^{-5}\right.$. $\left.\mathrm{M}: C_{\mathrm{Fe}(\mathrm{III}) \mathrm{CIT}}=10 \times 10^{-5} \mathrm{M}\right)$. Absorbance standard deviation for TC sample treated with Fe(III)CIT in ratio of 2:1 ranged 0.003-0.02, in ratio $1: 1$ was $0.01-0.02$, and SD in ratio $1: 2$ ranged was $0.002-0.08$

Figure 10a shows the fluorescence spectra of TC not subjected to UV-C rays measured during 10 days. Within 10 days, the fluorescence spectrum of TC solution

Fig. 10 The fluorescence spectra of TC in water solution measured during 10 days: a TC not treated with UV, b treated with UV for $10 \mathrm{~min}$, c treated with UV for $20 \mathrm{~min}$. Fluorescence standard deviation for TC sample not treated with UV ranged from 0 to 16 , for TC treated with UV for $10 \mathrm{~min}$-from 0 to 7 , for TC treated with UV for 20 min ranged from 0 to 7

practically did not show any change (Fig. 10a). Figure 10b, c shows the fluorescence spectra of TC subjected to UV-C rays. Subjecting this solution to UV irradiation for $10 \mathrm{~min}$ (Fig. 10b) or $20 \mathrm{~min}$, Figure 10c did not cause any shifts in 
location of maximum fluorescence spectrum within 10 days, whereas a 10-min ozonation of TC solution $\left(5 \times 10^{-5} \mathrm{M}\right)$ resulted in a shift of fluorescence maximum of TC solution to $\lambda_{\max }=531 \mathrm{~nm}$ (Fig. 11a). Figure 11a shows a fluorescence spectrum of pure TC too, normalized for the maximum fluorescence of the product. Longer ozonation period of TC solution $\left(5 \times 10^{-5} \mathrm{M} ; 20 \mathrm{~min}\right.$, Fig. 11b) resulted in a new fluorescence band of TC degradation product, with the fluorescence maximum at $\lambda_{\max }=523 \mathrm{~nm}$. This degradation product turned out to be stable within 9 days because the wavelength of fluorescence maximum did not shift in this period. However, a change in intensity of fluorescence was observed (a drop to $50 \%$ ) after 10 days. It should be emphasized that the TC solutions subjected to a 10-min ozonation treatment apparently contained a different TC decomposition product (with fluorescence maximum at $\lambda=531 \mathrm{~nm}$ ) which was
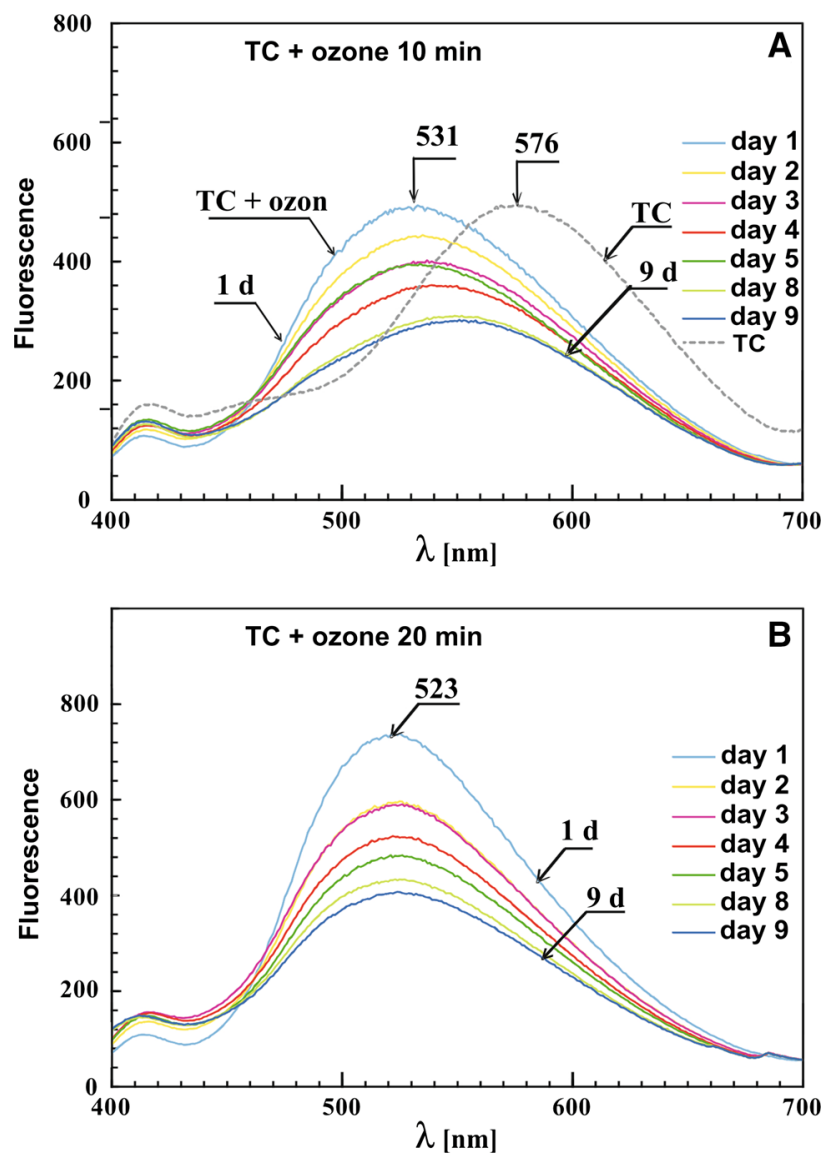

Fig. 11 The fluorescence spectra of tetracycline (TC) in water solution measured during 10 days: a treated with ozone for $10 \mathrm{~min}$, b treated with ozone for $20 \mathrm{~min}$. a was supplemented with fluorescence spectrum of TC not treated with ozone, normalized to fluorescence maximum of TC treated with ozone. Fluorescence standard deviation for TC sample treated with ozones for $10 \mathrm{~min}$ ranged from 0 to 8 , for TC treated with ozone for $20 \mathrm{~min}$ ranged from 3 to 21 not stable, as within 9 days the fluorescence maximum of solution shifted back by $20 \mathrm{~nm}$ toward the spectrum of pure TC. Also in the case of this product, the intensity of fluorescence decreased by $50 \%$ during a 9-day period.
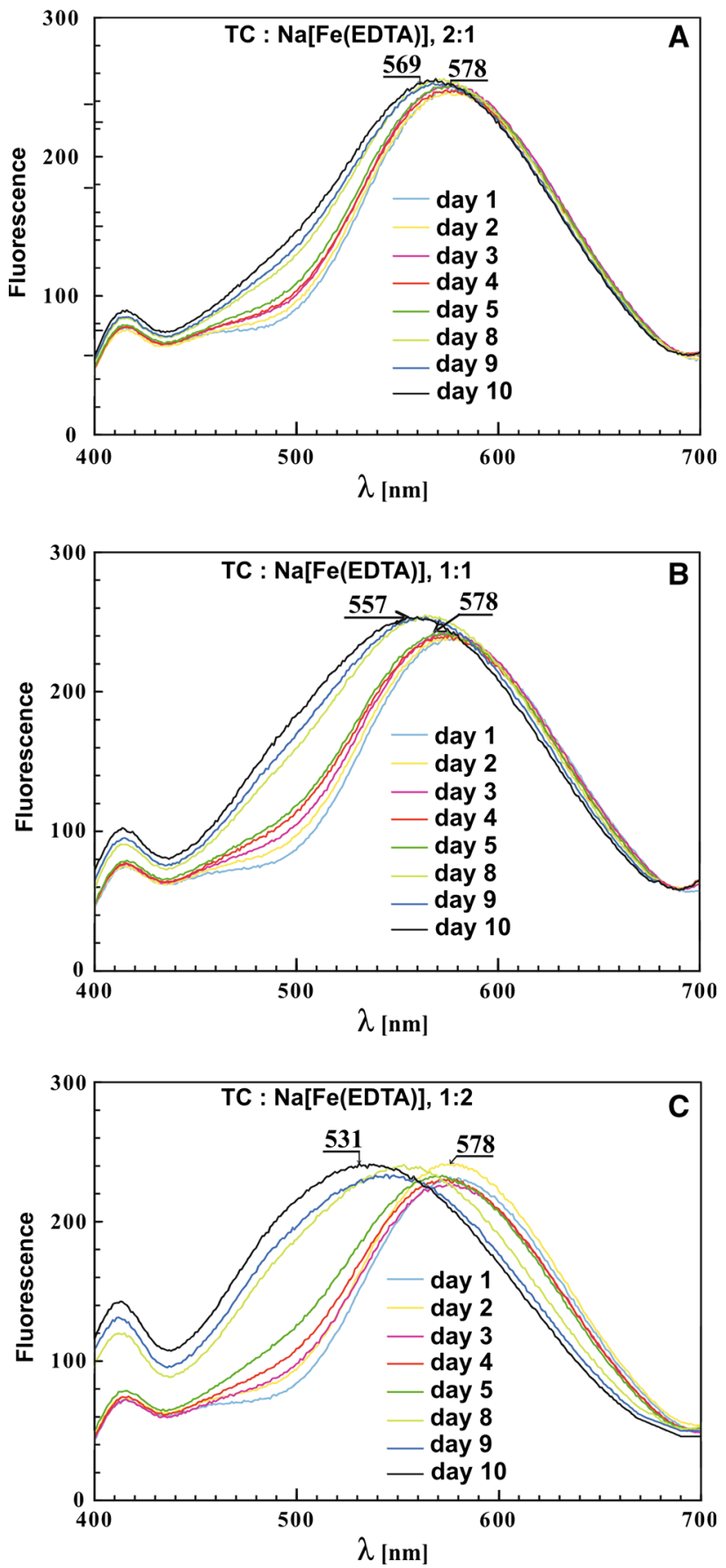

Fig. 12 The changes of fluorescence spectra of TC (during 10 days) for different initial molar concentration ratios of $\mathrm{TC}$ to $\mathrm{Na}[\mathrm{Fe}(\mathrm{EDTA})]:$ a $2: 1 \quad\left(C_{\mathrm{TC}}=5 \times 10^{-5} \mathrm{M}: C_{\mathrm{Na}[\mathrm{Fe}(\mathrm{EDTA})]}=2.5 \times\right.$ $\left.10^{-5} \mathrm{M}\right), \mathbf{b} 1: 1\left(C_{\mathrm{TC}}=5 \times 10^{-5} \mathrm{M}: C_{\mathrm{Na}[\mathrm{Fe}(\mathrm{EDTA})]}=5 \times 10^{-5} \mathrm{M}\right)$, c $1: 2\left(C_{\mathrm{TC}}=5 \times 10^{-5} \mathrm{M}: C_{\mathrm{Na}[\mathrm{Fe}(\mathrm{EDTA})]}=10 \times 10^{-5} \mathrm{M}\right)$. Fluorescence standard deviation for TC sample treated by $\mathrm{Na}[\mathrm{Fe}(\mathrm{EDTA})]$ in ratio of $2: 1$ ranged $1-15$, in ratio $1: 1$ was $2-5$, and $\mathrm{SD}$ in ratio $1: 2$ was 1-8 

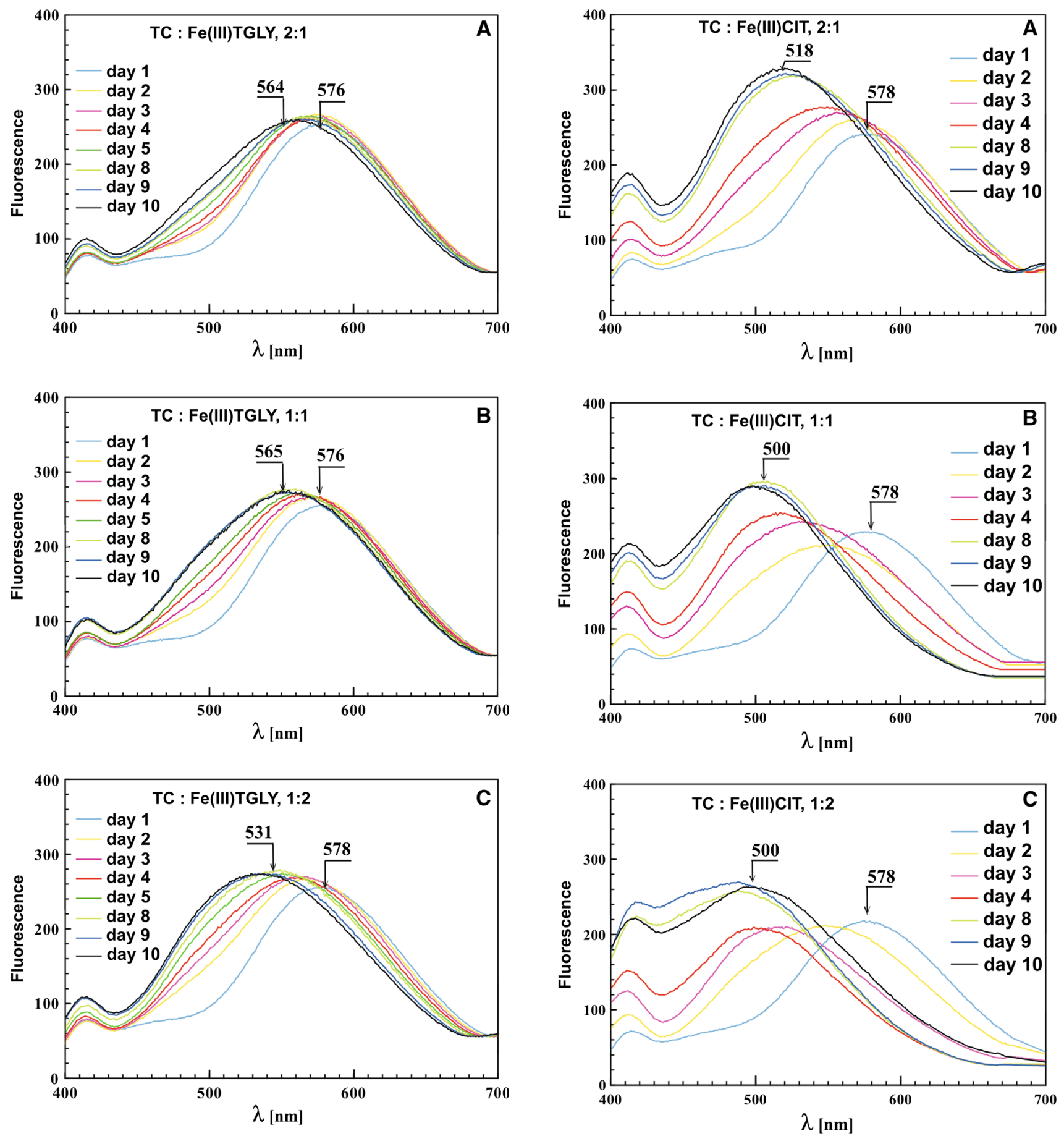

Fig. 13 The changes of fluorescence spectra of TC (during 10 days) for different initial molar concentration ratios of TC to Fe(III)TGLY: a $2: 1 \quad\left(C_{\mathrm{TC}}=5 \times 10^{-5} \mathrm{M}: C_{\mathrm{Fe}(\mathrm{III}) \mathrm{TGLY}}=2.5 \times 10^{-5} \mathrm{M}\right)$, b $1: 1$ $\left(C_{\mathrm{TC}}=5 \times 10^{-5} \mathrm{M}: C_{\mathrm{Fe}(\mathrm{III}) \mathrm{TGLY}}=5 \times 10^{-5} \mathrm{M}\right), \quad$ c $1: 2 \quad\left(C_{\mathrm{TC}}=\right.$ $\left.5 \times 10^{-5} \mathrm{M}: C_{\mathrm{Fe}(\mathrm{III}) \mathrm{TGLY}}=10 \times 10^{-5} \mathrm{M}\right)$. Fluorescence standard deviation for TC sample treated with Fe(III)TGLY in ratio of 2:1 ranged $0-6$, in ratio $1: 1$ was $0-7$, and SD in ratio $1: 2$ was $0-10$

Ozonation affects not only TC solutions. Many examples of other compounds are known which are degraded by ozone. The use of ozonation in water treatment includes

Fig. 14 The changes of fluorescence spectra of TC (during 10 days) for different initial molar concentration ratios of TC to Fe(III)CIT: a $2: 1 \quad\left(C_{\mathrm{TC}}=5 \times 10^{-5} \mathrm{M}: C_{\mathrm{Fe}(\mathrm{III}) \mathrm{CIT}}=2.5 \times 10^{-5} \mathrm{M}\right), \quad$ b $1: 1$ $\left(C_{\mathrm{TC}}=5 \times 10^{-5} \mathrm{M}: C_{\mathrm{Fe}(\mathrm{III}) \mathrm{CIT}}=5 \times 10^{-5} \mathrm{M}\right), \quad$ c $1: 2 \quad\left(C_{\mathrm{TC}}=\right.$ $\left.5 \times 10^{-5} \mathrm{M}: C_{\mathrm{Fe}(\mathrm{III}) \mathrm{CIT}}=10 \times 10^{-5} \mathrm{M}\right)$. Absorbance standard deviation for TC sample treated with Fe(III)CIT in ratio of 2:1 ranged $2-6$, in ratio $1: 1$ was $2-7$, and SD in ratio $1: 2$ was $2-6$

comprehensive oxidation pathways, which can lead to the creation of various by-products, some of which can be harmful to living organisms. During hydroxylation, 
ofloxacin is divided at an unsaturated double bond of the heterocyclic ring (Tay and Madehi 2015). In addition, ozonation leads to the degradation of water solutions of oxalic acid and oxamic acid, and the final products of organic compounds oxidate (Orge et al. 2015).

In our experiments, TC ozonation $\left(5 \times 10^{-5} \mathrm{M}\right)$ gave rise to two new bands of fluorescence with the maxima at $\lambda=523$ and $531 \mathrm{~nm}$, apparently corresponding to the TC disintegration products (Fig. 11). Two products of TC degradation were also observed by Dalmázio et al. (2007), using HPLC-UV, ESI-MS, and LC-APCI-MS methods. According to these authors, one of TC degradation products is unstable and both products result from TC oxidation by insertion of one or two oxygen atoms.

Figure 12 shows the changes of fluorescence spectrum under the influence of $\mathrm{Na}[\mathrm{Fe}(\mathrm{EDTA})$ in a TC solution. Fluorescence spectrum of the solution containing TC and $\mathrm{Na}[\mathrm{Fe}$ (EDTA) gradually shifted toward a shorter wavelength (Fig. 12a-c) during 10 days. At concentration ratio $1: 2\left(C_{\mathrm{TC}}=5 \times 10^{-5} \mathrm{M}: C_{\mathrm{EDTA}}=10 \times 10^{-5} \mathrm{M}\right)$, a new product of TC degradation appeared, with maximum fluorescence at $\lambda_{\max }=531 \mathrm{~nm}$ after 10 days (shifted by $47 \mathrm{~nm}$ relative to the fluorescence spectrum of pure TC) (Fig. 12c). This new product was clearly detectable after 9 days.

A product with similar properties was formed after 10 days in solution of TC treated with Fe(III)TGLY (Fig. 13). It also had the fluorescence maximum at $\lambda=531 \mathrm{~nm}$ (Fig. 13c).

In solution treated with Fe(III)CIT (Fig. 14), the rate of TC degradation was even higher. Already, at day 4 with concentration ratio $1: 2 \quad\left(C_{\mathrm{TC}}=5 \times 10^{-5}\right.$ $\left.\mathrm{M}: C_{\mathrm{CIT}}=10 \times 10^{-5} \mathrm{M}\right)($ Fig. $14 \mathrm{c})$ fluorescence spectrum of the solution distinctly shifted to the short-wave regiontoward the spectrum of decomposition product $\left(\lambda_{\max }=500 \mathrm{~nm}\right)$. An almost complete TC degradation took place, and the fluorescence spectrum lost the features typical of a TC solution. The maximum levels of fluorescence and corresponding wavelengths of forming TC degradation products are given in Table 2 .

Table 2 The decrease in absorbance of TC solution (a measure of TC concentration) after 10 days of experiment

\begin{tabular}{lrll}
\hline Treatment & $\begin{array}{l}\text { TC } \\
\text { degradation } \\
\text { percent }\end{array}$ & $\begin{array}{l}\text { Degradation } \\
\text { time }\end{array}$ & $\begin{array}{l}\text { Fluorescence max } \\
\text { peaks of degradation } \\
\text { product }(\mathrm{nm})\end{array}$ \\
\hline Ozone & $55 \pm 2$ & Immediately & $523 \pm 1,531 \pm 1$ \\
UV-C & $3 \pm 1$ & 10 days & - \\
Na[Fe(EDTA)] & $42 \pm 5$ & 10 days & $531 \pm 1$ \\
$\mathrm{Fe}(\mathrm{III}) \mathrm{TGLY}$ & $36 \pm 3$ & 10 days & $531 \pm 1$ \\
$\mathrm{Fe}(\mathrm{III}) \mathrm{CIT}$ & $90 \pm 8$ & 10 days & $500 \pm 3$
\end{tabular}

a No significant decrease was observed during the 10 days period of observations after ozonation treatment
The observed shifts in fluorescence maxima (Figs. 11, $12,13,14)$ did not result from $\mathrm{pH}$ changes within the range of $\mathrm{pH} 5.0$ to 6.0 (that have indeed occurred) but they clearly suggest the formation of TC degradation products. The experiments carried out by (Mojica et al. 2014) and verified by ourselves (data not shown) prove that the changes in $\mathrm{pH}$ of $\mathrm{TC}$ solution without more profound chemical modifications of this antibiotic do not result in changes of solution fluorescence.

Metal cations $\mathrm{Cr}(\mathrm{III}), \mathrm{Mn}(\mathrm{II}), \mathrm{Fe}(\mathrm{III}), \mathrm{Co}(\mathrm{II}), \mathrm{Ni}(\mathrm{II})$, $\mathrm{Zn}(\mathrm{II}), \mathrm{Cd}(\mathrm{II}), \mathrm{Hg}$ (II), $\mathrm{Pb}(\mathrm{II}), \mathrm{Al}(\mathrm{III})$, and $\mathrm{UO}_{2}$ (II) form stable complexes with tetracycline (Ghandour et al. 1992). Formation of TC complexes with iron can be used for tetracycline removal from water. Wang et al. (2015) indicate that during the degradation of TC, complexes of the antibiotic with iron (III) are probably formed, followed by oxidation of iron (III). Fe(III)CIT complexes are very photoreactive, and the optimum photodegradation conditions are at pH 6.9 (Feng et al. 2012).

Among iron chelates used in our experiments for the degradation of tetracycline, the most effective were $\mathrm{Fe}(\mathrm{III}) \mathrm{CIT}$ and $\mathrm{Na}[\mathrm{Fe}(\mathrm{EDTA})]$. After using $\mathrm{Fe}(\mathrm{III}) \mathrm{CIT}$ degraded TC in $90 \%$ when it was used at the highest concentration $\left(10 \times 10^{-5} \mathrm{M}\right)$, while the degree of degradation caused by $\mathrm{Na}[\mathrm{Fe}(\mathrm{EDTA})]$ was lower by over a half. The quantum efficiency of TC solution fluorescence varied within 10 days, depending on the properties of the TC degradation products. The intensity of fluorescence of products formed by the action $\mathrm{Na}[\mathrm{Fe}(\mathrm{EDTA})]$ or Fe(III)TGLY on TC increased only slightly within 10 days, by 4 and $7 \%$, respectively. The action of $\mathrm{Fe}(\mathrm{IIII}) \mathrm{CIT}$ on TC resulted in a much bigger increase of fluorescence (20\% in 10 days). The ozonation treatment, on the other hand, resulted in formation of a different product with a fluorescence maximum at $\lambda=523 \mathrm{~nm}$ and a drop of fluorescence of the solution by $50 \%$. The quantum efficiencies of these products fluorescence could not be precisely determined, however, as the solutions contained detectable amounts of unmodified TC even after 10 days of the experiment.

\section{Conclusion}

Tetracycline $\left(5 \times 10^{-5} \mathrm{M}\right)$ contaminant of water can be deactivated very efficiently by ozonation-application of $12 \mathrm{mg}$ ozone resulted in immediate degradation of the antibiotic. Within 10 days of the experiment, a $55 \%$ drop of TC absorbance was observed as a result of ozonation treatment. The fluorescence spectra indicate the formation of two TC degradation products with maxima of fluorescence at $\lambda=523 \mathrm{~nm}$ and $\lambda=531 \mathrm{~nm}$. The product with fluorescence maximum at $\lambda=523 \mathrm{~nm}$ is stable-is not converted into another product during 10 days. 
The chemical treatments with iron(III) sodium ethylenediaminetetraacetate, iron(III) citrate and iron(III) trisglycinate were less efficient, the best of them being iron(III) citrate which degraded tetracycline by $90 \%$ during 10 days of the experiment, leading to the formation of a tetracycline degradation product with a fluorescence maximum at $\lambda=500 \mathrm{~nm}$. The action of iron(III) sodium ethylenediaminetetraacetate and iron(III) trisglycinate on tetracycline resulted in formation of a product with a fluorescence maximum at $\lambda=531 \mathrm{~nm}$. The degree of tetracycline degradation, measured after 10 days for these compounds, was 42 and $36 \%$, respectively. Our experiments enabled us to follow the temporal changes in tetracycline level during 10 days after ozonation or UV-C treatment or 10 days of action of iron(III) sodium ethylenediaminetetraacetate, iron(III) trisglycinate and iron(III) citrate in tetracycline solution.

Acknowledgments The present study was financially supported by project National Science Centre Poland, UMO-2011/01/B/NZ9/ 02646 .

\section{Compliance with ethical standards}

Conflict of interest The authors declare that they have no conflict of interest.

Open Access This article is distributed under the terms of the Creative Commons Attribution 4.0 International License (http:// creativecommons.org/licenses/by/4.0/), which permits unrestricted use, distribution, and reproduction in any medium, provided you give appropriate credit to the original author(s) and the source, provide a link to the Creative Commons license, and indicate if changes were made.

\begin{tabular}{|c|c|}
\hline \\
\hline \multicolumn{2}{|l|}{$\begin{array}{l}\text { Abbreviation } \\
\text { TC }\end{array}$} \\
\hline $\mathrm{Na}[\mathrm{Fe}(\mathrm{EDTA})]$ & $\begin{array}{l}\text { Iron(III) sodium } \\
\text { ethylenediaminetetraacetate }\end{array}$ \\
\hline Fe(III)TGLY & Iron(III) trisglycinate \\
\hline $\mathrm{Fe}(\mathrm{III}) \mathrm{CIT}$ & Iron(III) citrate \\
\hline
\end{tabular}

\section{References}

Abd-Elmoneim MM, El-Ajaily MM, Maihub AA, El-Hassiy ZA (2008) Investigation and biological activity of some nonpolar iron amino acid chelates. Pak J Nutr 7(5):673-678

Adams C, Wang Y, Loftin K, Meyer M (2002) Removal of antibiotics from surface and distilled water in conventional water treatment processes. J Environ Eng ASCE 128(3):253-260

Ando K, Manta N (2015) Iron(III) citrate, substantially free of betairon hydroxide oxide. Patent US 2015/0025138 A1

Andreozzi R, Canterino M, Marotta R, Paxeus N (2005) Antibiotic removal from wastewaters: the ozonation of amoxicillin. J Hazard Mater 122(3):243-250
Bagda E, Ersan M, Bagda E (2013) Investigation of adsorptive removal of tetracycline with sponge like, Rosa canina gall extract modified, polyacrylamide cryogels. J Environ Chem Eng 1:1079-1084

Chander Y, Kumar K, Goyal SM, Gupta SC (2005) Antibacterial activity of soil-bound antibiotics. J Environ Qual 34:1952-1957

Chen WR (2008) Interactions of tetracycline antibiotics with dissolved metal ions and metal oxides. PhD thesis, School of Civil and Environmental Engineering, Georgia Institute of Technology

Dalmázio I, Almeida MO, Augusti R, Alves TMA (2007) Monitoring the degradation of tetracycline by ozone in aqueous medium via atmospheric pressure ionization mass spectrometry. J Am Soc Mass Spectrom 18(4):679-687

FDA (2002) Ultraviolet radiation for the processing and treatment of food. Code of Federal Regulations 21 Part 179, vol 39

Feng X, Wang Z, Chen Y, Tao T, Wu F (2012) Multivariateparameter optimization for photodegradation of tetracycline by $\mathrm{Fe}(\mathrm{III})$-citrate complexes at near-neutral pH. J Environ Eng 138(8):873-879

Ghandour MA, Azab HA, Hassan A, Ali AM (1992) Potentiometric studies on the complexes of tetracycline (TC) and oxytetracyclin (OTC) with some metal ions. Monat Chem 123:51-58

Gu C, Karthikeyan KG, Sibley SD, Pedersen JA (2007) Complexation of the antibiotic tetracycline with humic acid. Chemosphere 66(8):1494-1501

Gupta VK, Jain R, Mittal A, Saleh TA, Nayak A, Agarwal S, Sikarwar S (2012) Photo-catalytic degradation of toxic dye amaranth on $\mathrm{TiO}_{2} / \mathrm{UV}$ in aqueous suspension. Mater Sci Eng C 32(1):12-17

Gupta VK, Kumar R, Nayak A, Saleh TA, Barakat MA (2013) Adsorptive removal of dyes from aqueous solution onto carbon nanotubes: a review. Adv Colloid Interface Sci 193-194:24-34

Hamscher G, Pawelzick HT, Höper H, Nau H (2005) Different behavior of tetracyclines and sulfonamides in sandy soils after repeated fertilization with liquid manure. Environ Chem 24(4):861-868

Hao R, Xiao X, Zuo X, Nan J, Zhang W (2012) Efficient adsorption and visible-light photocatalytic degradation of tetracycline hydrochloride using mesoporous BiOI microspheres. J Hazard Mater 209-210:137-145

Kang J, Liu H, Zheng YM, Qu J, Chen JP (2011) Application of nuclear magnetic resonance spectroscopy, Fourier transform infrared spectroscopy, UV-Visible spectroscopy and kinetic modeling for elucidation of adsorption chemistry in uptake of tetracycline by zeolite beta. J Coll Interface Sci 354(1):261-267

Kang J, Liu H, Zheng YM, Qua J, Chen JP (2010) Systematic study of synergistic and antagonistic effects on adsorption of tetracycline and copper onto a chitosan. J Colloid Interface Sci 344:117-125

Kong W, Li Ch, Dolhi JM, Li S, He J, Qiao M (2012) Characteristics of oxytetracycline sorption and potential bioavailability in soils with various physical-chemical properties. Chemosphere 87:542-548

Kwon SI, Owens G, Ok YS, Lee DB, Jeon WT, Kim JG, Kim KR (2011) Applicability of the Charm II system for monitoring antibiotic residues in manure-based composts. Waste Manag 31(1):39-44

Lezehari M, Baudu M, Bouras O, Basly JP (2012) Fixed-bed column studies of pentachlorophenol removal by use of alginateencapsulated pillared clay microbeads. J Colloid Interface Sci 379(1):101-106

Li G, Zhang D, Wang M, Huang J, Huang L (2013) Preparation of activated carbons from Iris tectorum employing ferric nitrate as dopant for removal of tetracycline from aqueous solutions. Ecotoxicol Environ Saf 98:273-282 
Liu M, Lv G, Mei L, Wang X, Xing X, Liao L (2014) Degradation of tetracycline by birnessite under microwave irradiation. Adv Mater Sci Eng. doi:10.1155/2014/409086

Llorca M, Gros M, Rodríguez-Mozaz S, Barceló D (2014) Sample preservation for the analysis of antibiotics in water. J Chromatogr A $1369: 43-51$

Martínez-Carballo E, González-Barreiro C, Scharf S, Gans O (2007) Environmental monitoring study of selected veterinary antibiotics in animal manure and soils in Austria. Environ Poll 148:1-10

Miao XS, Bishay F, Chen M, Metcalfe CD (2004) Occurrence of antimicrobials in the final effluents of wastewater treatment plants in Canada. Environ Sci Technol 38(13):3533-3541

Mohanta T, Goel S (2014) Prevalence of antibiotic-resistant bacteria in three different aquatic environments over three seasons. Environ Monit Assess 186(8):5089-5100

Mojica ERE, Nguyen E, Rozov M, Bright FV (2014) pH-dependent spectroscopy of tetracycline and its analogs. J Fluoresc 24(4):1183-1198

Naddeo V, Ricco D, Scannapieco D, Belgiorno V (2012) Degradation of antibiotics in wastewater during sonolysis, ozonation, and their simultaneous application: operating conditions effects and processes evaluation. Int J Photoenergy 2012:1-7

O'Connor S, Aga DS (2007) Analysis of tetracycline antibiotics in soil: advances in extraction, clean-up, and quantification. Trac Trend Anal Chem 26(6):456-465

Orge CA, Pereira MFR, Faria JL (2015) Photocatalytic ozonation of model aqueous solutions of oxalic and oxamic acids. Appl Catal B Environ 174-175:113-119

Resource Book for Sixth-form Practical Chemistry (2015) Synthesis of an iron(III)-EDTA complex. Co-produced by The Chinese University of Hong Kong, Education and Manpower Bureau and Hong Kong Examinations and Assessment Authority. http:// www.cuhk.edu.hk/chem/en/resources/f6resoursebk-eimg06. html. Accessed Aug 2015

Rosendahl I, Siemens J, Kindler R, Groeneweg J, Zimmermann J, Czerwinski S, Lamshöft M, Laabs V, Wilke BM, Vereecken H (2012) Persistence of the fluoroquinolone antibiotic difloxacin in soil and lacking effects on nitrogen turnover. J Environ Qual 41(4):1275-1283

Safari GH, Nasseri S, Mahvi AH, Yaghmaeian K, Nabizadeh R, Alimohammadi M (2015) Optimization of sonochemical degradation of tetracycline in aqueous solution using sono-activated persulfate process. J Environ Health Sci Eng 13:76

Saleh TA, Gupta VK (2014) Processing methods, characteristics and adsorption behavior of tire derived carbons: a review. Adv Colloid Interface Sci 211:93-101
Sidrach-Cardona R, Hijosa-Valsero M, Marti E, Balcázar JL, Becares E (2014) Prevalence of antibiotic-resistant fecal bacteria in a river impacted by both an antibiotic production plant and urban treated discharges. Sci Total Environ 488-489:220-227

Tay KS, Madehi N (2015) Ozonation of ofloxacin in water: byproducts, degradation pathway and ecotoxicity assessment. Sci Total Environ 520:23-31

Ternes TA, Stüber J, Herrmann N, McDowell D, Ried A, Kampmann M, Teiser B (2003) Ozonation: a tool for removal of pharmaceuticals, contrast media and musk fragrances from wastewater? Water Res 37(8):1976-1982

U.S. Environmental Protection Agency (2009). http://www.epa.gov/ osw/inforesources/data/br09/br2009rpt.pdf

Vukosav P, Mlakar M, Tomiší V (2012) Revision of iron(III)-citrate speciation in aqueous solution. Voltammetric and spectrophotometric studies. Anal Chim Acta 745:85-91

Wang H, Yao H, Sun P, Pei J, Li D, Huang CH (2015) Oxidation of tetracycline antibiotics induced by $\mathrm{Fe}(\mathrm{III})$ ions without light irradiation. Chemosphere 119:1255-1261

Wang H, Yao H, Sun P, Li D, Huang CH (2016) Transformation of tetracycline antibiotics and $\mathrm{Fe}(\mathrm{II})$ and $\mathrm{Fe}(\mathrm{III})$ species induced by their complexation. Environ Sci Technol 50(1):145-153

Wei X, Wu SC, Nie XP, Yediler A, Wong MH (2009) The effects of residual tetracycline on soil enzymatic activities and plant growth. J Environ Sci Health B 44:461-471

Wittmer A, Heisele A, McArdell CS, Böhler M, Longree P, Siegrist H (2015) Decreased UV absorbance as an indicator of micropollutant removal efficiency in wastewater treated with ozone. Water Sci Technol 71(7):980-985

Wu X, Wie Y, Zheng J, Zhao X, Zhong W (2011) The behavior of tetracyclines and their degradation products during swine manure composting. Bioresour Technol 102:5924-5931

Zhang HM, Zhang MK, Gu GP (2008) Residues of tetracyclines in livestock and poultry manures and agricultural soils from North Zhejiang Province. J Ecol Rural Environ 24(3):69-73

Zhao L, Dong YH, Wang H (2010) Residues of veterinary antibiotics in manures from feedlot livestock in eight provinces of China. Sci Total Environ 408:1069-1075

Zhao L, Xue F, Yu B, Xie J, Zhang X, Wu R, Wang R, Hu Z, Yang ST, Luo J (2015) $\mathrm{TiO}_{2}$-graphene sponge for the removal of tetracycline. J Nanopart Res 17(1):9

Ziółkowska A, Piotrowicz-Cieślak AI, Margas M, Adomas B, NałęczJawecki G (2015) Accumulation of tetracycline, oxytetracycline and chlortetracycline in pea (Pisum sativum L.). Fresen Environ Bull 24(4a):1386-1391 